\title{
Angiotensin II induces tumor progression and fibrosis in intrahepatic cholangiocarcinoma through an interaction with hepatic stellate cells
}

\author{
KOICHI OKAMOTO ${ }^{1}$, HIDEHIRO TAJIMA ${ }^{1}$, TETSUO OHTA ${ }^{1}$, SHINICHI NAKANUMA ${ }^{1}$, HIRONORI HAYASHI ${ }^{1}$, \\ HISATOSHI NAKAGAWARA ${ }^{1}$, ICHIRO ONISHI ${ }^{1}$, HIROYUKI TAKAMURA ${ }^{1}$, ITASU NINOMIYA ${ }^{1}$, \\ HIROHISA KITAGAWA ${ }^{1}$, SACHIO FUSHIDA ${ }^{1}$, TAKASHI TANI ${ }^{1}$, TAKASHI FUJIMURA ${ }^{1}$, \\ MASATO KAYAHARA $^{1}$, SHINICHI HARADA ${ }^{2}$, TOMOHIKO WAKAYAMA ${ }^{3}$ and SHOICHI ISEKI ${ }^{3}$ \\ ${ }^{1}$ Gastroenterologic Surgery, Department of Oncology, Division of Cancer Medicine; ${ }^{2}$ Center for Biomedical Research \\ and Education; ${ }^{3}$ Department of Histology and Embryology, Graduate School of Medical Science, \\ Kanazawa University, 13-1 Takara-Machi, Kanazawa, Ishikawa 920-8640, Japan
}

Received June 30, 2010; Accepted August 13, 2010

DOI: 10.3892/ijo_00000776

\begin{abstract}
Intrahepatic cholangiocarcinoma (ICC) is characterized as a highly fatal tumor with poor prognosis because of its strong progression, early invasion, widespread metastasis and rich cancerous stroma. Although it is widely accepted that fibroblasts facilitate stromal fibrosis and tumor progression, the mechanisms of the interaction between cancer cells and activated fibroblasts have not been fully elucidated thus far. In this study, we demonstrate the presence of angiotensin II (AngII) in ICC tissues and explore the interaction between hepatic stellate cells (HSCs) and ICC cells as one of the sources of stromal fibrosis and tumor progression through the interaction of the AngII/AngII type 1 receptor (AT-1) axis. The concentrations of AngII in ICC tissues were significantly higher than those of $\mathrm{HCC}$ and normal liver. Two human ICC cell lines (HuCCT-1, CCKS-1) and a human HSC cell line (LI-90) expressed AT-1 mRNA and protein. The proliferative activity of ICC cells and HSCs to which AngII was added dose-dependently increased and AT-1 antagonist inhibited the proliferative effects. HSCs to which AngII was added showed a higher expression of $\alpha$-smooth muscle actin ( $\alpha$-SMA, a marker of activated HSCs and myofibroblasts), glial fibrillary acidic protein (GFAP, a specific marker of HSCs) and collagen type I than control cells. AT-1 antagonist also inhibited the activation and transformation of HSCs stimulated by AngII. These findings suggested that locally
\end{abstract}

Correspondence to: Dr Koichi Okamoto, Gastroenterologic Surgery, Department of Oncology, Division of Cancer Medicine, Graduate School of Medical Science, Kanazawa University, 13-1 Takara-Machi, Kanazawa, Ishikawa 920-8640, Japan E-mail:kookka5151@gmail.com

Key words: intrahepatic cholangiocarcinoma, angiotensin II, angiotensin II type 1 receptor, hepatic stellate cell, fibrosis formed AngII in ICC tissues plays a role in the proliferation and activation of ICC cells and HSCs expressing AT-1 as a growth factor in autocrine and paracrine fashions. Our mechanistic findings provide the first insight into an autocrine and paracrine AngII-initiated signaling pathway that regulates ICC proliferation and fibrosis.

\section{Introduction}

Although both hepatocellular carcinoma (HCC) and intrahepatic cholangiocarcinoma (ICC) are primary liver tumors, the amount of collagen tissue in each tumor is completely different. It is well known that the characteristics of ICC are the hypovascularity and richness of cancerous stroma as determined by diagnostic imaging compared with those of HCC. Although it is widely accepted that fibroblasts facilitate stromal fibrosis and tumor progression, the mechanisms and origins of such activated fibroblasts have not been fully elucidated until now (1).

Terada et al demonstrated that ICC tissues had a greater tendency to highly express trypsinogen/trypsin and cathepsin $\mathrm{B}$ and that no HCC tissues had any expression of trypsinogen (2). Human pancreatic cancer cells expressed and secreted pancreatic cationic-type trypsinogen in vitro, which is spontaneously converted into active trypsin at acidic $\mathrm{pH}(\mathrm{pH} 4.5-$ $5.5)$, in contrast to anionic-type trypsinogen, which is not. Cationic-type trypsinogen could increase the invasive ability and cell proliferation of pancreatic cancer cells (3). In previous reports, it was described that the high expression of a specific G-protein-coupled receptor, protease-activated receptor-2 (PAR-2), was observed in pancreatic cancer cells and fibroblasts around tumor tissue $(4,5)$. PAR-2 activated by its agonists, including trypsin and tryptase, plays an important role in promoting the proliferation of pancreatic cancer (6).

Meanwhile, Arakawa et al (7) demonstrated that trypsin generated angiotensin II (AngII) from human plasma protein in the absence of angiotensin converting enzyme (ACE) 
at weakly acidic $\mathrm{pH}$ 7.0). Our previous report showed that pancreatic cancer tissues had higher trypsinogen expression and higher AngII concentrations than other solid tumors, such as HCC and colorectal cancer (8). We demonstrated that angiotensinogen in the blood was directly converted to AngII and in vivo evidence suggested a renin-angiotensin system (RAS)-independent cascade in pancreatic cancer tissues. Locally formed AngII was thought to act on pre-existing pancreatic arteries around the tumor, leading to the formation of hypoperfusive regions, so-called hypovascular or avascular regions. Some reports have described the expression of specific G-protein-coupled receptor, AngII type 1 receptor (AT-1), in cancer cells and the role of AngII/AT-1 axis in cancer proliferation, as well as the influence of the environment surrounding cancer cells as a potent mitogen (9).

Meanwhile, it has been reported that pancreatic cancer cells induce fibrosis by stimulating pancreatic stellate cells to proliferate and synthesize matrix $(11,12)$. Hepatic stellate cells (HSCs) are well known as an important component of the background liver associated with chronic liver diseases and liver tumors. The proliferation and activation of HSCs are the dominant events in liver injury, inflammation and fibrosis that render the cells responsive to cytokines and other local stimuli. Following liver injury or stimulation by various attractants, including monocyte chemoattractant protein (MCP)-1, transforming growth factor (TGF)- 31 , vascular endothelial growth factor (VEGF) or AngII, HSCs undergo a response known as activation, which is the transformation of quiescent cells into proliferative and fibrogenic myofibroblasts (activated HSCs), thereby modulating inflammatory cell infiltration and subsequent hepatic fibrosis (13-16). HSCs are similar to pancreatic stellate cells and may contribute to the desmoplastic reaction associated with primary and metastatic liver tumors $(17,18)$. Recently, Okabe et al reported that HSCs may differentiate into myofibroblasts in the cancerous stroma of ICC tissues and promote the invasiveness and cell proliferation of cancer cells on coculturing with ICC cells in a paracrine fashion (19).

We hypothesize that activated HSCs are one of the resources of stromal fibrosis especially in collagen-rich liver tumors, such as ICC, which has a higher level of AngII through the co-interaction between cancer cells and HSCs. The aim of the present work was to investigate the presence of a RAS-independent AngII-generating system in ICC tissues and to clarify the role of AngII in ICC progression in an autocrine fashion. The interaction between fibrosisassociated cells and cancer cells may induce the characteristic differences between collagen-poor HCC and collagen-rich ICC, which have fundamental differences in the amounts of tumor-derived trypsin and locally formed AngII. The hypoperfusive and fibrotic environment may make ICC tissues more malignant and resistant to various therapies. We also explored the paracrine interaction between ICC cells and HSCs in tumor fibrosis through the AngII/AT-1 axis.

\section{Materials and methods}

Human tissue samples. The current study included ten specimens of primary ICC (well to poorly differentiated adenocarcinoma) that were surgically resected between 1998 and 2009. The average age of ICC patients was 67 years (range 50-84 years). All patients had stage I-IVB disease on the basis of the general rules for the clinical and pathological study of primary liver cancer (20). Histologically, normal liver tissues were obtained from non-tumoral portions of resected ICC specimens. In addition, 11 cases of HCC were examined for comparative study.

Immediately following surgical removal, the tissue samples were frozen in liquid nitrogen and stored at $-80^{\circ} \mathrm{C}$ until the time of the assay for measuring AngII concentration. For immunohistochemical examination, the materials employed in this study, 20\% formalin-fixed and paraffin-embedded specimens, were retrieved from the surgical pathology files of the Pathology Section of Kanazawa University Hospital (School of Medicine, Kanazawa University, Kanazawa, Japan).

Cell culture. Two human ICC cell lines [HuCCT-1, obtained from the Cell Resource Center for Biochemical Research, Tohoku University, Sendai, Japan (21) and CCKS-1, obtained from the Department of Human Pathology, Kanazawa University Graduate School of Medicine (22)], and a human hepatic stellate cell line [LI-90, obtained from the Human Science Cell Bank, Saitama, Japan (23)] were used. ICC cell lines were maintained at $37^{\circ} \mathrm{C}$ in a $5 \% \mathrm{CO}_{2}$ incubator and grown in RPMI-1640 medium supplemented with $2 \mathrm{mM}$ glutamine, $10 \%$ fetal bovine serum (FBS), $100 \mathrm{U} / 1$ penicillin and $100 \mu \mathrm{g} / \mathrm{ml}$ streptomycin. LI-90 cell lines were maintained at $37^{\circ} \mathrm{C}$ in a $5 \% \mathrm{CO}_{2}$ incubator and grown in Dulbecco's modified Eagle's medium (DMEM) supplemented with $2 \mathrm{mM}$ glutamine, 10\% FBS, $100 \mathrm{U} / 1$ penicillin and $100 \mu \mathrm{g} / \mathrm{ml}$ streptomycin.

Reagents and antibodies. AngII was used at concentrations of $1,10,100$ or $1000 \mathrm{nM}$ (9). An active compound, telmisartan, which is a novel, long-acting, selective AT-1 receptor antagonist, was purchased from Sigma-Aldrich (St. Louis, MO, USA) and used at concentrations of 100 and $1000 \mathrm{nM}$, according to a previous report (24). Transforming growth factor (TGF)- $\$ 1$ was purchased from Sigma-Aldrich and was used at a concentration of $10 \mathrm{ng} / \mathrm{ml}$, according to a previous report (25). For primary antibodies, we obtained rabbit polyclonal AT-1 antibody (Santa Cruz Biotechnology, CA, USA), mouse monoclonal collagen type I antibody (Santa Cruz), mouse monoclonal $\alpha$-smooth muscle actin ( $\alpha$-SMA) antibody (Sigma-Aldrich), mouse monoclonal $\beta$-actin antibody (Sigma-Aldrich) and rabbit polyclonal glial fibrillary acidic protein (GFAP) antibody (Dako Cytomation, Glostrup, Denmark).

Measurement of angiotensin II in tissues. The determination of AngII content was performed as follows. Briefly, tissue samples were homogenized at $4^{\circ} \mathrm{C}$ in saline containing $0.1 \mathrm{~N}$ $\mathrm{HCl}$ and $5 \%$ urinastatin. The homogenate was sedimented at $10,000 \mathrm{x} \mathrm{g}$ for $30 \mathrm{~min}$ at $4^{\circ} \mathrm{C}$, and the supernatant was used for radioimmunoassay of AngII using the florisil method (florisil absorption and elution with acetone-hydrochloric acid solution) as described previously (26). This method is more sensitive, specific and useful for routine clinical 
investigation. Parallel frozen tissue samples were homogenized in phosphate-buffered saline (PBS).

Immunohistochemistry. The expression of AT-1 in ICC specimens was examined immunohistochemically using each primary antibody. To identify the antigen in the tissue, deparaffinized sections were pretreated by autoclaving in $10 \%$ citric acid buffer $(\mathrm{pH} 8.0)$ at $120^{\circ} \mathrm{C}$ for $15 \mathrm{~min}$. After pretreatment with protein block serum (Dako Cytomation, Kyoto, Japan) for $10 \mathrm{~min}$ and in $2 \%$ skim milk for $20 \mathrm{~min}$ to block non-specific reactions, the sections were incubated with each primary antibody at $4^{\circ} \mathrm{C}$ overnight. The Envision ${ }^{+}$ polymer solution (horseradish peroxidase, HRP, secondary antibody, Dako Cytomation) was then applied for $1 \mathrm{~h}$. The reaction products were developed in $0.02 \%$ 3,3'-diaminobenzidine tetrahydrochloride (DAB) solution containing $0.1 \% \mathrm{H}_{2} \mathrm{O}_{2}$. The sections were then lightly counterstained with hematoxylin. The slides were examined under a fluorescence microscope (Olympus, Tokyo, Japan). Specimens were classified as positive when $>10 \%$ of cancer cells were stained.

Immunocytochemistry. The expressions of AT-1 in ICC cells and AT-1, $\alpha$-SMA and GFAP in HSCs were examined immunocytochemically using respective primary antibodies. The suspensions of each cancer cell were seeded on Lab Tek chamber slides (Nunc) and incubated for $24-48 \mathrm{~h}$ at $37^{\circ} \mathrm{C}$ in a humid atmosphere of $5 \% \mathrm{CO}_{2} / 95 \%$ air. The coverslips with cells were then fixed with methanol and acetone $1: 1(\mathrm{v} / \mathrm{v})$. After pretreatment with protein blocking serum for $10 \mathrm{~min}$ to block non-specific binding, immunostaining was performed using Envision+ System. Briefly, the slides were incubated with each primary antibody $(1: 50)$ at $4^{\circ} \mathrm{C}$ overnight. After washing, the Envision ${ }^{+}$polymer solution was applied for $1 \mathrm{~h}$. The reaction products were visualized via a DAB reaction. The cells were then lightly counterstained with hematoxylin and examined under a fluorescence microscope.

Western blot analysis. AT-1 was recovered from subconfluent HuCCT-1, CCKS-1 and LI-90 cells, which were harvested, washed in cold PBS and lysed in ice-cold lysis buffer [10 mM PBS ( $\mathrm{pH} 7.4), 1 \%$ NP40, $0.5 \%$ sodium deoxycholate, $0.1 \%$ SDS, $5 \mathrm{mM}$ EDTA] supplemented with $1 \%$ phenylmethylsulfonyl fluoride and a protease inhibitor cocktail for $30 \mathrm{~min}$ at $4^{\circ} \mathrm{C}$. The lysate was sonicated and centrifuged at $15,000 \mathrm{rpm}$ for $30 \mathrm{~min}$ at $4^{\circ} \mathrm{C}$ to remove debris, and the protein concentration was measured using a BCA Protein Assay Kit (Thermo Scientific, USA). Total protein was measured using a spectrophotometer. Extracted protein was used for Western blot analysis. In this analysis, $20 \mu \mathrm{g}$ of protein from each sample was loaded onto $12.5 \%$ sodium dodecyl sulfate-polyacrylamide gels (SDS-PAGE) and the proteins were transferred to a polyvinylidene difluoride (PVDF) membrane by the semi-dry blotting method. The membrane was washed for 10 min with blocking solution (0.1\% Tween-20; Ez Block, ATTO Corporation, Japan), blocked at room temperature for $30 \mathrm{~min}$ with blocking solution, and washed with washing solution $(0.1 \%$ Tween- 20 , Ez Wash; ATTO Corporation). The blots were incubated for $2 \mathrm{~h}$ at room temperature with each primary antibody against
AT-1 diluted at 1:500 with washing solution. The blots were incubated for $1 \mathrm{~h}$ with an HRP-conjugated anti-mouse antibody (against anti-AT-1 antibody diluted at 1:5000 with washing solution as a second antibody). Chemiluminescence was detected with the ECL Plus Western blotting detection system (GE Healthcare Bioscience, Japan) according to the supplier's recommendations. We also used two antibodies, $\alpha$-SMA and GFAP, for Western blot analysis as fibrous markers to measure the up- or down-regulation of the expressions of $\alpha$-SMA and GFAP in LI-90 incubated in medium with added AngII (100 nM) or TGF- $31(10 \mathrm{ng} / \mathrm{ml})$.

Extraction of RNA and reverse transcriptase polymerase chain reaction ( $R T-P C R$ ) for $A T-1$ and GAPDH $m R N A$. mRNA was isolated from HuCCT-1, CCKS-1 and LI-90 cell lines using TRI Reagent (Sigma-Aldrich). Then, $1 \mu \mathrm{g}$ of mRNA was used to synthesize first-strand cDNA with an RNeasy Mini Kit (Qiagen, USA) and QIA shredder (Qiagen), according to the manufacturer's instructions. PCR for AT-1 and GAPDH was performed with a Taq Man PCR Kit (Takara, Japan), according to the manufacturer's instructions. The AT-1 forward primer sequence was 5'- TCAACAAAAAT GAGCACGCTTT-3'; and the reverse was 5'-AAACATGGT GCAGGCTTCTTG-3' (the pair generated a 485-bp fragment) (27). The GAPDH oligonucleotide primer set (forward 5'-ACC ACAGTCCATGCCATCAC-3', reverse 5'-TCCACCACCCT GTTGCTGTA-3'; the pair generated a 452-bp fragment) was used as an internal standard. PCR was performed for 35 cycles (denaturation at $98^{\circ} \mathrm{C}$ for $15 \mathrm{sec}$, annealing at $58^{\circ} \mathrm{C}$ for $30 \mathrm{sec}$ and extension at $74^{\circ} \mathrm{C}$ for $45 \mathrm{sec}$ ). After PCR, $5 \mu 1$ samples of the products were subjected to $2.0 \%$ agarose gel electrophoresis and stained with ethidium bromide.

Cell proliferation assay. The proliferative effect of AngII on ICC and HSC cell lines was quantified using an MTT colorimetric assay with Cell Proliferation Kit I (Roche), according to the manufacturer's instructions. In brief, each cancer cell line $\left(5 \times 10^{3}\right.$ cells/well $)$ was grown in 96 -well flat-bottom microtiter plates in $100 \mu \mathrm{l}$ of medium including $1 \%$ FBS and incubated for $48-96 \mathrm{~h}$ at $37^{\circ} \mathrm{C}$ in a humidified atmosphere (e.g. $37^{\circ} \mathrm{C}, 5 \% \mathrm{CO}_{2}$ ). The medium contained different concentrations (1-1000 nM) of AngII or $10 \mathrm{ng} / \mathrm{ml}$ TGF-ß1. In some experiments, telmisartan was added to AngII treatment to make sure that the proliferative effect caused by AngII occurred through the AT- 1 receptor. After the incubation period, $10 \mu 1$ of the MTT labeling reagent (final concentration $0.5 \mathrm{mg} / \mathrm{ml}$ ) was added to each well, the microplate was incubated for $4 \mathrm{~h}$ in a humidified atmosphere (e.g. $37^{\circ} \mathrm{C}, 5 \%$ $\mathrm{CO}_{2}$ ) and then $100 \mu \mathrm{l}$ of the solubilization solution was added to each well. We allowed the plate to stand overnight in the incubator in a humidified atmosphere (e.g. $37^{\circ} \mathrm{C}, 5 \%$ $\mathrm{CO}_{2}$ ), then checked for complete solubilization of the purple formazan crystals and measured the spectrophotometric absorbance value of the samples using a microplate reader. The wavelength to measure absorbance of the formazan product is $595 \mathrm{~nm}$. The experiments were repeated in triplicate wells. Cell viability was calculated as follows: Cell number $(\%$ of control $)=($ absorbance of experimental wells $) /$ (absorbance of control wells) x $100(\%)$. 


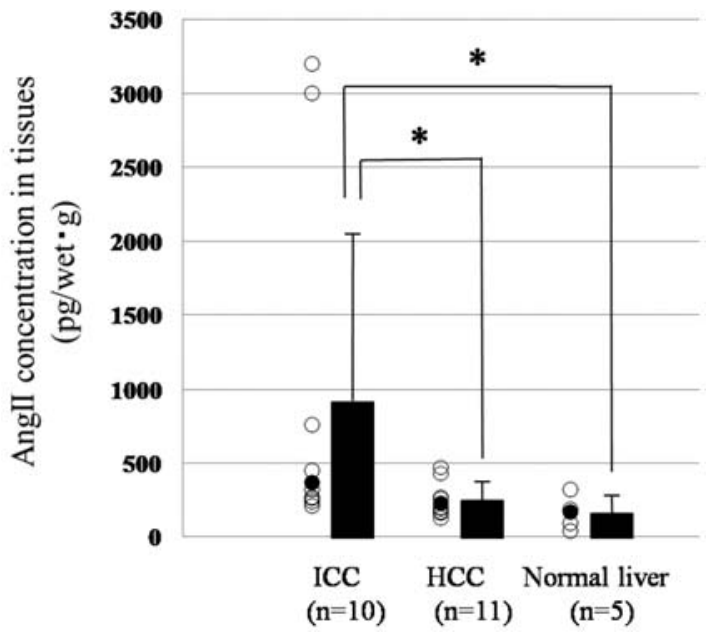

Figure 1. AngII concentration in tissue extracts of ICC, HCC and normal liver. AngII concentrations in ICC tissues were significantly higher than those of HCC and normal liver. ${ }^{*} \mathrm{P}<0.05$.

Fluorescent immunocytochemistry. LI-90 cells were grown on Lab-Tek chamber slides to 40-60\% confluence, serumdeprived overnight (DMEM + 1\% FBS) and then treated with AngII (100 nM) or TGF- 31 (10 ng/ml). In some experiments, telmisartan (1000 nM) was added to AngII treatment to make sure that the effect caused by AngII occurred through the AngII/AT1 axis. After fixation with $3.7 \%$ formalin, cells were blocked with protein blocking serum. Cells were incubated with the primary antibodies ( $\alpha$-SMA and GFAP) for $1 \mathrm{~h}$ at room temperature. Slides were then washed and incubated with the appropriate Alexa Fluor 488 and $592 \mathrm{~nm}$ phalloidin-conjugated (Molecular Probes Inc., Eugene, OR) specific secondary antibodies for double staining for $1 \mathrm{~h}$ at room temperature. Cells were then incubated with Hoechst 33258 for nuclear staining for 5 min and mounted with propyl gallate containing phenylenediamine under glass coverslips. Cells were then visualized for immunofluorescence with a laser scanning Olympus microscope at x10, x20 and x40 magnification.

Statistical analysis. Statistical analyses were carried out using an unpaired t-test except for the measurement of AngII concentration in tissues. In the measurement of AngII concentration in tissues, analysis was carried out using the Mann-Whitney U test. $\mathrm{P}<0.05$ was considered significant.

\section{Results}

Angiotensin II concentration in tissues. Tissue AngII concentration was determined radioimmunologically in tissue extracts of ICC $(n=10)$, HCC $(n=11)$ and normal liver $(n=5)$. The concentration was $908 \pm 1167 \mathrm{pg} / \mathrm{g}$ wet tissue in ICC, $244 \pm 111 \mathrm{pg} / \mathrm{g}$ wet tissue in HCC and $162 \pm 107 \mathrm{pg} / \mathrm{g}$ wet tissue in normal liver. Thus, AngII concentrations in ICC tissues were significantly higher than those of HCC and normal liver (Fig. 1).

Immunohistochemistry and immunocytochemistry. Immunohistochemistry for AT-1 was expressed in 14 of $16(87.5 \%)$
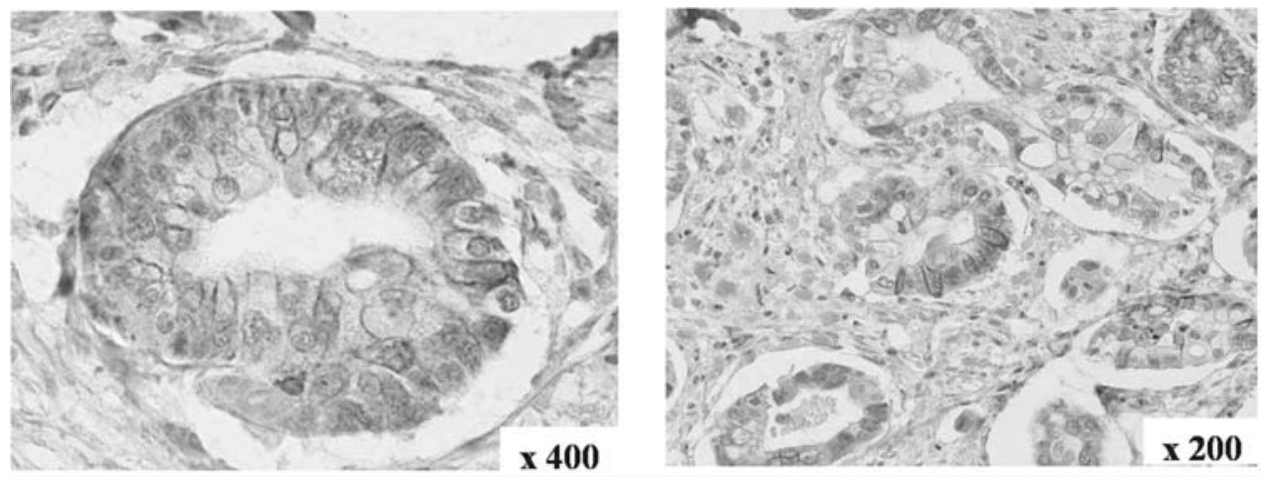

Figure 2. Expression of AT-1 in ICC tissues. AT-1 receptor immunoreactivity was evident in membranous and granular cytoplasmic patterns and was predominantly expressed in the center of the tumor. In addition, vascular endothelium, smooth muscle cells, fibroblasts and tumor-associated macrophages were strongly positive for AT-1 receptor.
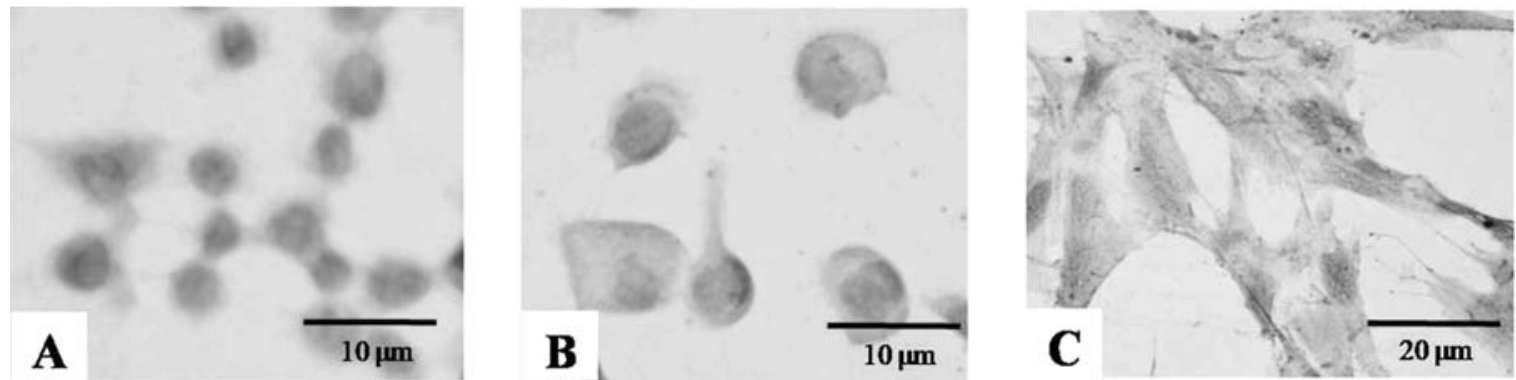

Figure 3. Immunocytochemistry for AT-1 in ICC cells and HSCs. (A, HuCCT-1; B, CCKS-1; C, LI-90) AT-1 expression was intense in HuCCT-1, CCKS-1 and LI-90 cells. AT-1 receptor immunoreactivity was evident in membranous and granular cytoplasmic patterns. 


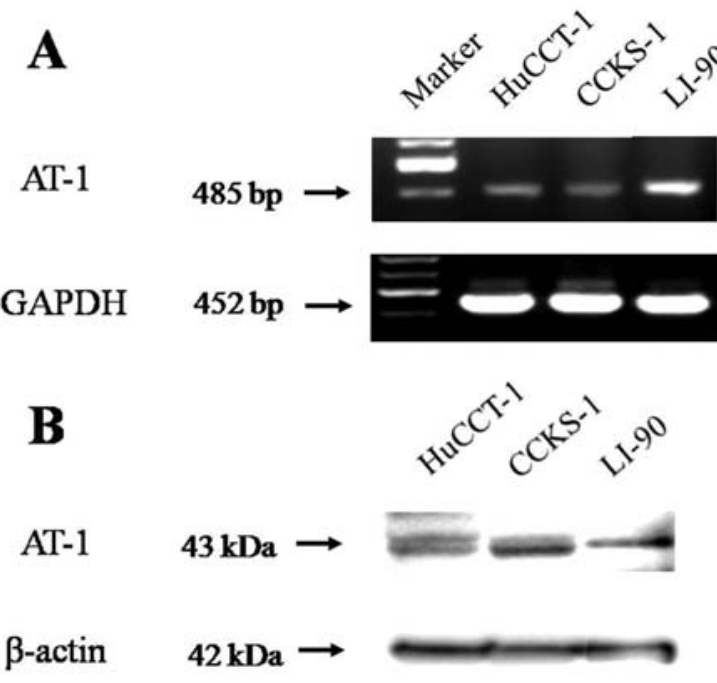

Figure 4. Expression of AT-1 mRNA and protein in ICC cells and HSCs AT-1 expression at the mRNA level was detected in HuCCT-1, CCKS-1 and LI-90 cells (A). Western blot analysis also demonstrated AT-1 protein expression in all three cells types (B).

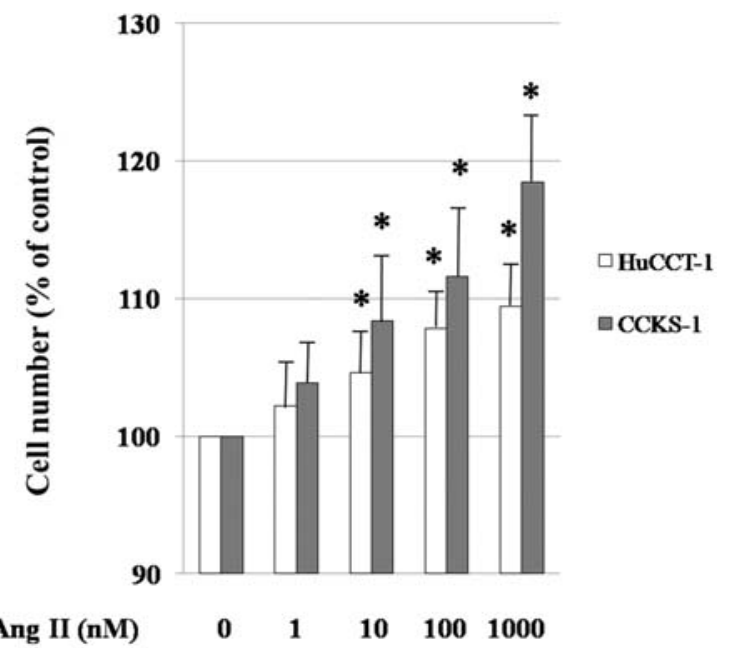

Figure 5. Proliferative effects of AngII in ICC cells. ICC cells were treated with different concentrations (1-1000 nM) of AngII, and their proliferative effects were quantified by MTT assay. AngII induced a dose-dependent increase in proliferative activity at concentrations of AngII from 10 to $1000 \mathrm{nM}$ for both HuCCT-1 and CCKS-1 cells. Results are the means \pm SD of triplicate experiments. ${ }^{*} \mathrm{P}<0.05$ compared with control (untreated) cells by unpaired t-test.

surgical specimens of human ICC. AT-1 receptor immunoreactivity was evident in membranous and granular cytoplasmic patterns and was predominantly expressed in the center of the tumor (Fig. 2). In addition, vascular endothelium, smooth muscle cells, fibroblasts and tumor-associated macrophages were strongly positive for AT-1 receptor. In immunocytochemistry, AT-1 expression was intense in HuCCT-1, CCKS-1 and LI-90 cells. AT-1 receptor immunoreactivity was evident in membranous and granular cytoplasmic patterns (Fig. 3).

RT-PCR and Western blot analysis of AT-1 in human ICC and HSC cells. AT-1 expression at the mRNA level was detected in HuCCT-1, CCKS-1 and LI-90 cells (485 bp,

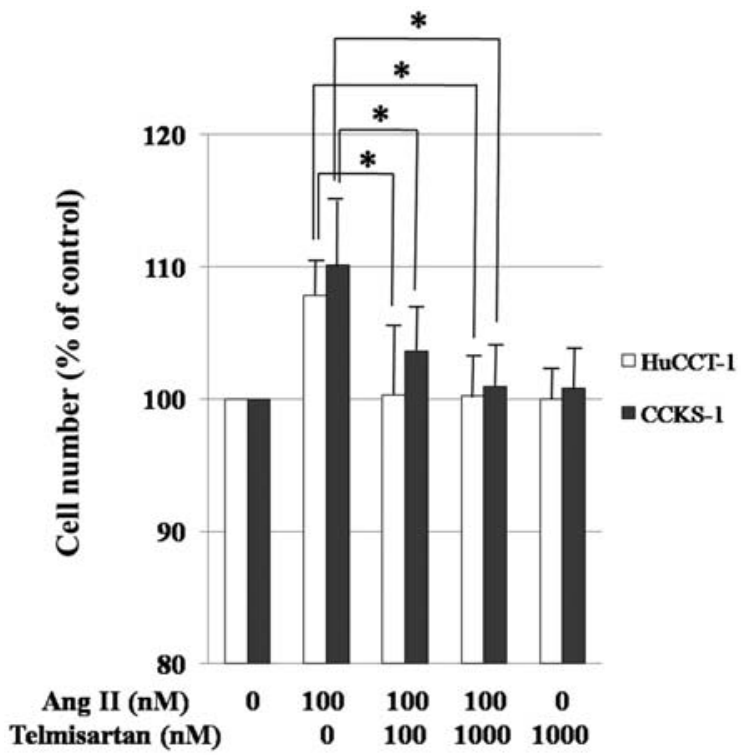

Figure 6. Inhibitory effect of AT-1 antagonist, telmisartan, against proliferating ICC cells to which AngII was added. AngII-induced proliferative response was significantly inhibited by 100 and $1000 \mathrm{nM}$ telmisartan. A decrease in proliferation was not observed in the telmisartan alone group compared with that of vehicle-treated cells. Results are the means \pm SD of triplicate experiments. ${ }^{*} \mathrm{P}<0.05$ versus $100 \mathrm{nM}$ AngII.

Fig. 4A). Western blot analysis also demonstrated AT-1 protein expression in all three cells $(43 \mathrm{kDa})$ and $\mathrm{AT}-1$ protein expression mirrored that of mRNA (Fig. 4B).

Effect of angiotensin II on ICC and HSC cell proliferation. To examine the effect of AngII, AT-1 receptor agonist, on the proliferation of ICC and HSC cells, HuCCT-1, CCKS-1 and LI-90 were treated with AngII or TGF- 11 and the proliferative effects were quantified by MTT assay. After incubation for $48 \mathrm{~h}$, cell proliferation was significantly and dosedependently increased by AngII at concentrations from 1 to $1000 \mathrm{nM}$ in HuCCT-1 and CCKS-1 cells (Fig. 5). In addition, we determined whether the AngII-induced proliferative response was inhibited by a specific AT-1 receptor antagonist, telmisartan. Telmisartan significantly inhibited the $100 \mathrm{nM}$ AngII-induced proliferative response at a concentration of $1000 \mathrm{nM}$ in both HuCCT-1 and CCKS-1 cells (Fig. 6). A decrease in proliferation was not observed in the telmisartan alone group compared with that of the control cells (vehicletreated cells). Therefore, these results demonstrate that the suppressive effect of telmisartan on cell growth resulted from the inhibition of AngII as a specific AT-1 receptor antagonist.

In LI-90 cells with each concentration of AngII, cell numbers dose-dependently increased at concentrations from 1 to $100 \mathrm{nM}$. Telmisartan significantly inhibited the $100 \mathrm{nM}$ AngII-induced proliferative response at a concentration of $100 \mathrm{nM}$ (Fig. 7).

Effect of AngII on activation and transformation in HSCs. It has been reported that GFAP is expressed in quiescent or partially activated HSCs and is known as a cell-specific marker of HSCs. $\alpha$-SMA is also known as a cell-specific marker of activated HSCs and myofibroblasts. HSCs transform into 


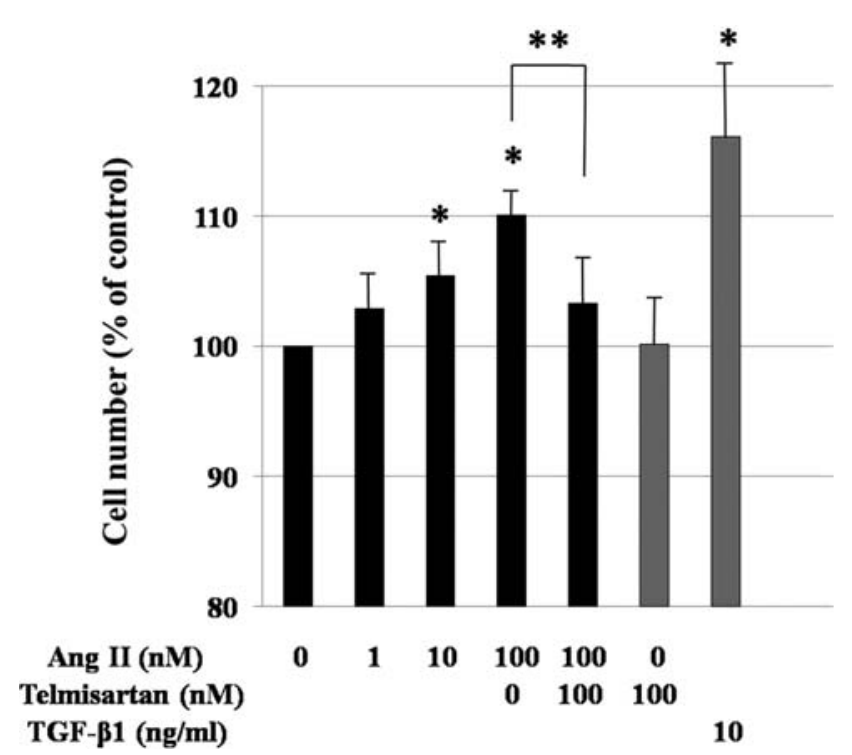

Figure 7. Proliferative effects of AngII in HSCs. LI-90 cells treated with each concentration of AngII (1-100 nM) dose-dependently increased in number at concentrations of AngII from 10 to $100 \mathrm{nM}$. Telmisartan completely inhibited the $100 \mathrm{nM}$ AngII-induced proliferative response at a concentration of $100 \mathrm{nM}$. Results are the means $\pm \mathrm{SD}$ of triplicate experiments. ${ }^{*} \mathrm{P}<0.05$ versus control. ${ }^{* *} \mathrm{P}<0.05$ versus $100 \mathrm{nM}$ AngII.

myofibroblasts and the expression of $\alpha$-SMA in the cytoplasm of activated HSCs is enhanced when quiescent HSCs are stimulated by attractants. In immunocytochemistry, the expression of GFAP was ubiquitously found in the cytoplasm of almost all HSCs, but the expression of $\alpha$-SMA was only partially found in the cytoplasm of cultured HSCs. In fluorescent immunocytochemistry, when LI-90 cells were added to $100 \mathrm{nM}$ AngII, the number of $\alpha$-SMA-positive LI90 cells was increased (Fig. 8). Telmisartan at $1000 \mathrm{nM}$ inhibited the activation of LI-90 cells and the transformation to myofibroblasts cells. When $10 \mathrm{ng} / \mathrm{ml}$ TGF- $\beta 1$ was added to LI-90 cells, the cells were activated and transformed into myofibroblasts. In Western blot analysis, when LI-90 cells were added to $100 \mathrm{nM} A n g \mathrm{II}$, the protein expression of $\alpha$ SMA, GFAP and collagen type I significantly increased (Fig. 9).

\section{Discussion}

Classically, RAS has been considered a hormonal circulating system. This circulating RAS plays an important role in the maintenance of blood pressure, electrolyte balance and fluid homeostasis (28). Meanwhile, recent reports have suggested that AngII is strongly associated with inflammatory diseases and cancer progression in various organs (29-31). Locally expressed tissue RAS components, including angiotensinogen, renin and AngII receptors, may be involved in the regulation of individual tissue functions, independent of circulating RAS.

AT-1 activation by AngII is proposed to signal mitogenactivated protein kinases (MAPKs), primarily via G proteins,
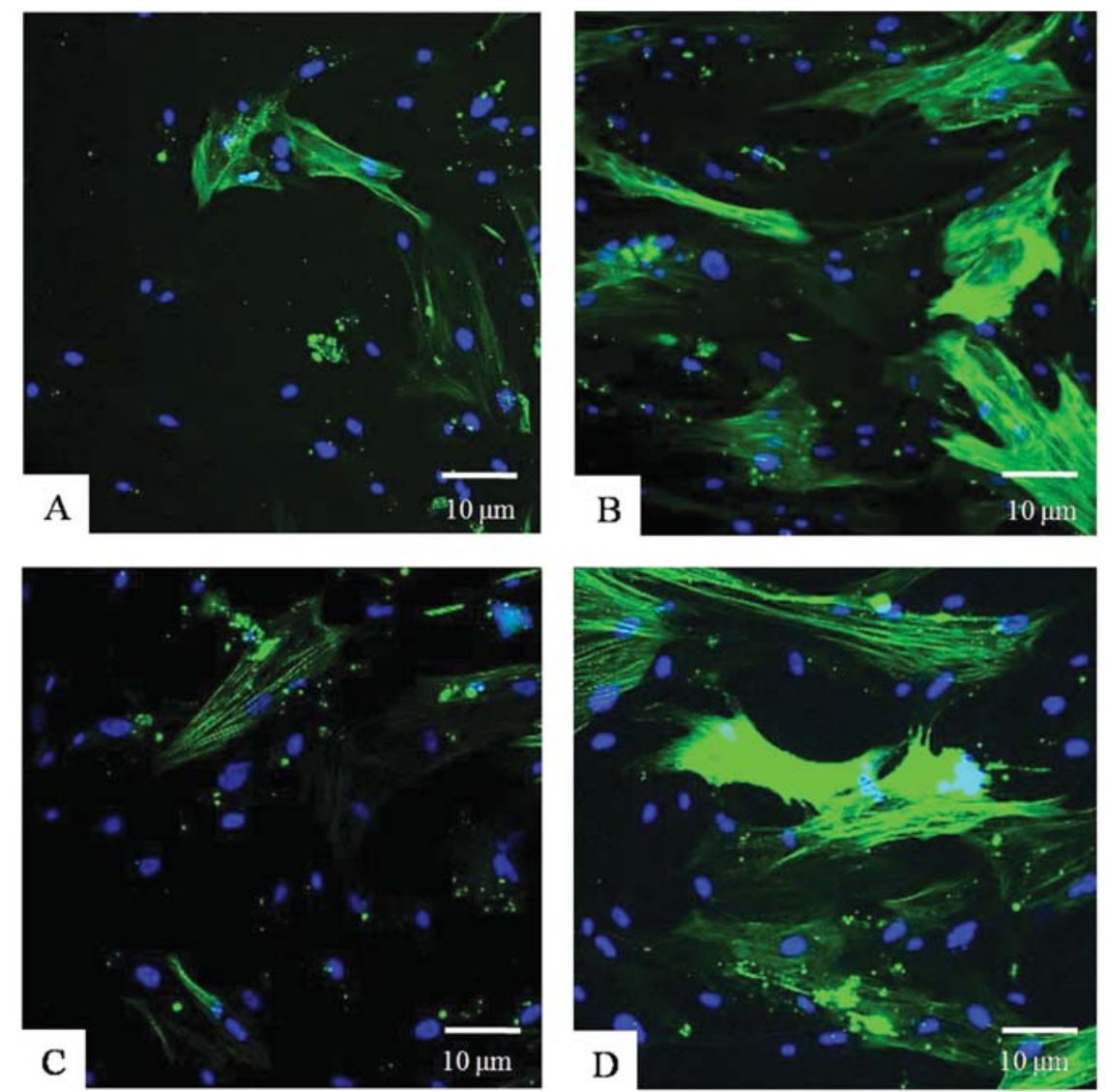

Figure 8. Fluorescent immunocytochemistry of AngII-induced activation and transformation of LI-90 cells (green, $\alpha$-SMA; blue, nuclei). When LI-90 cells were added to AngII, the number of $\alpha$-SMA-positive cells increased (A, control cells; B, $100 \mathrm{nM}$ AngII-treated cells). Telmisartan inhibited the activation of cells (C, AngII $100 \mathrm{nM}+$ Telmisartan $100 \mathrm{nM}$ ). Addition of $10 \mathrm{ng} / \mathrm{ml}$ TGF-ß31 also increased the number of $\alpha$-SMA-positive cells (D). 


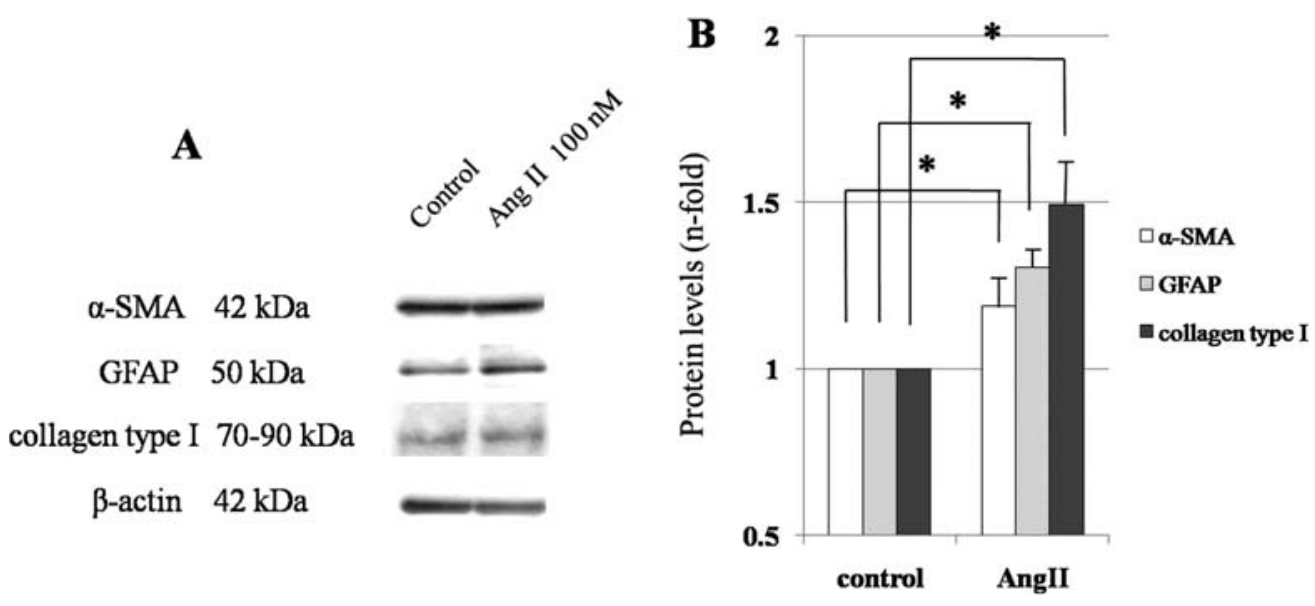

Figure 9. LI-90 cells were incubated with $100 \mathrm{nM}$ AngII. Representative Western blot results (A). Data are the mean \pm SD of three independent experiments (B). ${ }^{*} \mathrm{P}<0.05$ versus control.

in multiple ways. AT-1 activates focal adhesion kinase (FAK) and this enzyme activates Src, Ras and Raf, which in turn activate MAPKs resulting in the final activation of extracellular signal-regulated kinase (ERK) that participates in the phosphorylation of signal transducers and activators of transcription (STATs). Phosphorylated STATs are translocated to the nucleus, where they promote the transcription of genes that participate in cell hypertrophy and hyperplasia, as well as interferon- $\alpha, \mathrm{VEGF}$, fibroblast growth factor (FGFb), platelet-derived growth factor (PDGF), Bcl-2 and Bcl-xL, which block the caspase cascade, inhibiting apoptosis (30). Nuclear factor- $\kappa \mathrm{B}(\mathrm{NF}-\kappa \mathrm{B})$ plays a critical role in the regulation of cell survival. NF- $\kappa \mathrm{B}$ activation leads to anti-apoptosisrelated gene transcription including the inhibition of apoptosis protein (IAP) and Bcl-2 families, thereby providing a survival-promoting signal and inhibiting cell apoptosis (32). Survivin, a member of the IAP family, is expressed in the most common cancer cells, and plays an important role in resistance to radiotherapy $(33,34)$. Amaya et al have demonstrated that ERK1/2 and NF- $\mathrm{BB}$ activated by AngII enhance the expression of anti-apoptotic proteins, including survivin and Bcl-XL, and significantly prevent cancer cell apoptosis in pancreatic cancer cells in vitro. Their study suggested that AngII enhances cell proliferation and chemoresistance of cancer cells through the activation of ERK and $\mathrm{NF}-\kappa \mathrm{B}$ via transactivation of epidermal growth factor (EGF) receptor 9).

AngII is occasionally reported to be a stimulating factor in HSC activation and the production of various cytokines and chemokines. Activated HSCs to which AngII was added promoted the production of TGF- $\beta$ and were an important source of extracellular matrix (ECM) including collagens (types I, III and IV), fibronectin, undulin, elastin, laminin, hyaluronan and proteoglycans (13-16). We demonstrated that the activation-dependent up-regulation of $\alpha$-SMA, GFAP and collagen I expression occurred in LI-90 cells stimulated by AngII. It was also demonstrated that AngII receptor blocker (ARB) inhibited HSC proliferation, activation and transdifferentiation into myofibroblasts. Our study specifically addressed the in vitro behavior of HSCs to which AngII was added; therefore, we monitored cell-specific markers for
HSC activation, namely, $\alpha$-SMA and GFAP. In liver tissue, GFAP is expressed in quiescent or partially activated HSCs but not in perivascular myofibroblasts. Therefore, the increased expression levels of GFAP in AngII-treated cells reveal the increase in the overall number of HSCs and can therefore be utilized as a specific HSC proliferation marker. $\alpha$-SMA is well known to be a marker for activated HSCs and myofibroblasts. The increased expression of $\alpha$-SMA, positive correlation to collagen expression and the fibrosis-dependent enhanced expression of $\alpha$-SMA emphasize the importance of HSCs in AngII-induced activation (36,37).

Myofibroblasts can arise from activated HSCs, hepatocytes, bone-marrow-derived cells and possibly endothelial cells. Many studies suggest that myofibroblasts facilitate tumor fibrosis, tumor growth and cancer progression (17-19,38-40). The source of myofibroblasts and other activated fibroblasts within tumors is still debated, but HSCs have become recognized as one of the sources of cancerous stroma of liver tumors.

Tumor progression and fibrosis are pivotal aspects of malignant tumors, although their exact molecular mechanisms with respect to tumor-stromal interactions remain to be clarified. Several factors, including TGF- $\beta$, hepatocyte growth factor (HGF), EGF, VEGF, trypsinogen and AngII, are regarded as candidate factors involved in cross-talk in tumor-stromal interactions $(9,10,38)$. Recent reports have demonstrated the roles of stromal-cell-derived factor- 1 (SDF-1) and its specific receptor, CXCR4, in tumor fibrosis and cell proliferation, migration, survival and metastasis of cancer cells (41-43). It has been demonstrated that SDF-1 released from stromal fibroblasts was responsible for the migration of cancer cells expressing CXCR4. It has also been reported that bone-marrow-derived fibroblasts can contribute to the tumor stromal reaction and tissue fibrosis. This suggests that bone marrow may be a source of tissue fibroblasts, which are one of the components of cancer-induced stroma, and bone-marrow-derived activated fibroblasts were recruited into cancer-induced stroma in late stages of cancer (39). Carcinoma-associated fibroblasts (CAFs) are thought to promote the growth of cancer cells, angiogenesis and stromal fibrosis by recruiting endothelial progenitor cells through the 
interaction between SDF-1 secreted from CAFs and CXCR4 (40).

In conclusion, the present study demonstrated that ICC tissues had high AngII concentrations and that this locally formed AngII was associated with the tumor microenvironment. The interaction between ICC cells and HSCs through the AngII/AT-1 axis was suggested to have autocrine and paracrine synergistic effects on tumor progression and cancer fibrogenesis, and to make ICC highly malignant. A better understanding of the interplay between ICC cells and cancerous stroma will be important in developing strategies for improved tumor therapy that take into account the influence of the tumor microenvironment on tumor survival and growth. Additionally, we showed that some important effects of AngII antagonist are involved in tumor progression and cancerous stroma in ICC tissues. Targeting the AngII signaling pathway may not only affect the vascular dynamic state in cancer tissues, but also be a novel, efficient strategy for treating high-grade neoplasms with rich cancerous stroma.

\section{References}

1. Kalluri R and Zeisberg M: Fibroblasts in cancer. Nat Rev Cancer 6: 392-401, 2006.

2. Terada T, Ohta T, Minato H and Nakanuma Y: Expression of pancreatic trypsinogen/trypsin and cathepsin B in human cholangiocarcinomas and hepatocellular carcinomas. Hum Pathol 26: 746-752, 1995.

3. Tajima H, Ohta T, Ayman Elnemr, Yasui T, Kitagawa H, Fushida S, Kayahara M, Miwa K, Wakayama T, Iseki S and Yokoyama S: Enhanced invasiveness of pancreatic adenocarcinoma cells stably transfected with cationic trypsinogen cDNA. Int J Cancer 94: 699-704, 2001

4. Ohta T, Shimizu K, Yi S, Takamura H, Amaya K, Kitagawa $\mathrm{H}$, Kayahara M, Ninomiya I, Fushida S, Fujimura T, Nishimura G and Miwa K: Protease-activated receptor- 2 expression and the role of trypsin in cell proliferation in human pancreatic cancers. Int J Oncol 23: 61-66, 2003

5. Uchima Y and Sawada T: Action of antiproteases on pancreatic cancer cells. J Pancreas 8: 479-487, 2007.

6. Nyberg P, Ylipalosaari M, Sorsa T and Salo T: Trypsins and their role in carcinoma growth. Exp Cell Res 312: 1219-1228, 2006

7. Arakawa K and Maruta H: Ability of kallikrein to generate angiotensin II-like pressor substance and a proposed 'kinintensin enzyme system'. Nature 25: 705-706, 1980

8. Ohta T, Amaya K, Yi S, Kitagawa H, Kayahara M, Ninomiya I, Fushida S, Fujimura T, Nishimura G, Shimizu K and Miwa K: Angiotensin converting enzyme-independent, local angiotensin II-generation in human pancreatic ductal cancer tissues. Int J Oncol 23: 593-598, 2003.

9. Amaya K, Ohta T, Kitagawa H, Kayahra M, Takamura H, Fujimura T, Nishimura G, Shimizu K and Miwa K: Angiotensin II activates MAP kinase and NF- $\mathrm{kB}$ through angiotensin II type I receptor in human pancreatic cancer cells. Int J Oncol 25: 849-856, 2004.

10. Anandanadesan R, Gong Q, Chipitsyna G, Witkiewicz A, Yeo CJ and Arafat HA: Angiotensin II induces vascular endothelial growth factor in pancreatic cancer cells through an angiotensin II type 1 receptor and ERK1/2 signaling. J Gastrointest Surg 12: 57-66, 2008

11. Yen TW, Aardal NP, Bronner MP, Thorning DR, Savard CE, Lee SP and Bell RH Jr: Myofibroblasts are responsible for the desmoplastic reaction surrounding human pancreatic carcinomas. Surgery 131: 129-134, 2002.

12. Bachem MG, Schünemann M, Ramadani M, Siech M, Beger H, Buck A, Zhou S, Schmid-Kotsas A and Adler G: Pancreatic carcinoma cells induce fibrosis by stimulating proliferation and matrix synthesis of stellate cells. Gastroenterology 128: 907-921, 2005
13. Tingli J, Liao ZX, Ping J, Xu D and Wang H: Molecular mechanism of hepatic stellate cell activation and antifibrotic therapeutic strategies. J Gastroenterol 43: 419-428, 2008.

14. Gressner AM and Weiskirchen R: Modern pathogenetic concepts of liver fibrosis suggest stellate cells and TGF- $\beta$ as major players and therapeutic targets. J Cell Mol Med 10: 76-99, 2006.

15. Bataller R, Sancho-Bru P, Ginès P and Brenner DA: Liver fibrogenesis: a new role for the renin-angiotensin system. Antioxid Redox Signal 7: 1346-1355, 2005.

16. Svegliati-Baroni G, De Minicis S and Marzioni M: Hepatic fibrogenesis in response to chronic liver injury: novel insights on the role of cell-to-cell interaction and transition. Liver Int 28: 1052-1064, 2008

17. Tien YW, Wu YM, Lin WC, Lee HS and Lee PH: Pancreatic carcinoma cells stimulate proliferation and matrix synthesis of hepatic stellate cells. J Hepatol 51: 307-314, 2009.

18. Amann T, Bataille F, Spruss T, Mühlbauer M, Gäbele E, Schölmerich J, Kiefer P, Bosserhoff AK and Hellerbrand C: Activated hepatic stellate cells promote tumorigenicity of hepatocellular carcinoma. Cancer Sci 100: 646-653, 2009.

19. Okabe H, Beppu T, Hayashi H, Horino K, Masuda T, Komori H, Ishikawa $\mathrm{S}$, Watanabe $\mathrm{M}$, Takamori $\mathrm{H}$, Iyama $\mathrm{K}$ and $\mathrm{Baba} \mathrm{H}$ : Hepatic stellate cells may relate to progression of intrahepatic cholangiocarcinoma. Ann Surg Oncol 16: 2555-2564, 2009.

20. Liver Cancer Study Group of Japan: The general rules for the clinical and pathological study of primary liver cancer. 5th edition. Kanehara, Tokyo, pp17-27, 2008.

21. Miyagiwa M, Ichida T, Tokiwa T, Sato J and Sasaki H: A new human cholangiocellular carcinoma cell line (HuCC-T1) producing carbohydrate antigen 19/9 in serum-free medium. In Vitro Cell Dev Biol 25: 503-510, 1989.

22. Sugawara H, Yasoshima M, Katayanagi K, Kono N, Watanabe Y, Harada K and Nakanuma Y: Relationship between interleukin-6 and proliferation and differentiation in cholangiocarcinoma. Histopathology 33: 145-153, 1998.

23. Murakami K, Abe T, Miyazawa M, Yamaguchi M, Masuda T, Matsuura T, Nagamori S, Takeuchi K, Abe K and Kyogoku M: Establishment of a new human cell line, LI90, exhibiting characteristics of hepatic Ito (fat-storing) cells. Lab Invest 72: 731-739, 1995.

24. Isobe A, Takeda T, Sakata M, Miyake A, Yamamoto T, Minekawa R, Nishimoto F, Okamoto Y, Walker CL and Kimura T: Dual repressive effect of angiotensin II-type 1 receptor blocker telmisartan on angiotensin II-induced and estradiolinduced uterine leiomyoma cell proliferation. Hum Reprod 9: $1-7,2007$

25. Kubota S, Fridman R and Yamada Y: Transforming growth factor-beta suppresses the invasiveness of human fibrosarcoma cells in vitro by increasing expression of tissue inhibitor of metalloprotease. Biochem Biophys Res Commun 176: 129-136, 1991.

26. Morimoto T, Aoyama M, Gotoh E and Shionoiri H: A method of radioimmunoassay of plasma angiotensin II using Florisil. Folia Endocrinoa Jpn 59: 215-229, 1983.

27. Takayanagi R, Ohnaka K, Sakai Y, Nakao R, Yanase T, Haji M, Inagami T, Furuta $H$, Gou DF, Nakamuta $M$ and Nawata $H$ : Molecular cloning, sequence analysis and expression of a cDNA encoding human type 1 angiotensin II receptor. Biochem Biophys Res Commun 183: 910-906, 1992.

28. Peach MJ: Renin-angiotensin system: biochemistry and mechanisms of action. Physiol Rev 57: 313-370, 1977.

29. Huckle WR and Earp HS: Regulation of cell proliferation and growth by angiotensin II. Prog Growth Factor Res 5: 177-194, 1994.

30. Escobar E, Rodríguez-Reyna TS, Arrieta O and Sotelo J: Angiotensin II, cell proliferation and angiogenesis regulator: biologic and therapeutic implications in cancer. Curr Vasc Pharmacol 2: 385-399, 2004.

31. Ager EI, Neo J and Christophi C: The renin-angiotensin system and malignancy. Carcinogenesis 29: 1675-1684, 2008.

32. Bours V, Bentires-Alj M, Hellin AC, Viatour P, Robe P, Delhalle S, Benoit V and Merville MP: Nuclear factor-kappa B, cancer, and apoptosis. Biochem Pharmacol 60: 1085-1089, 2000.

33. Lee JU, Hosotani R, Wada M, Doi R, Kosiba T, Fujimoto K, Miyamoto Y, Tsuji S, Nakajima S, Nishimura Y and Imamura M: Role of Bcl-2 family proteins (Bax, Bcl-2 and $\mathrm{Bcl}-\mathrm{X}$ ) on cellular susceptibility to radiation in pancreatic cancer cells. Eur J Cancer 35: 1374-1380, 1999. 
34. Ambrosini G, Adida C and Altieri DC: A novel anti-apoptosis gene, survivin, expressed in cancer and lymphoma. Nat Med 3: 917-921, 1997.

35. Asanuma K, Moriai R, Yajima T, Yagihashi A, Yamada M, Kobayashi D and Watanabe N: Survivin as a radioresistance factor in pancreatic cancer. Jpn J Cancer Res 91: 1204-1209, 2000.

36. Salguero Palacios R, Roderfeld M, Hemmann S, Rath T, Atanasova S, Tschuschner A, Gressner OA, Weiskirchen R, Graf J and Roeb E: Activation of hepatic stellate cells is associated with cytokine expression in thioacetamide-induced hepatic fibrosis in mice. Lab Invest 88: 1192-1203, 2008.

37. Morini S, Carotti S, Carpino G, Franchitto A, Corradini SG, Merli M and Gaudio E: GFAP expression in the liver as an early marker of stellate cells activation. Ital J Anat Embryol 110: 193-207, 2005

38. Wynn TA: Cellular and molecular mechanisms of fibrosis. J Pathol 214: 199-210, 2008

39. Ishii G, Sangai T, Ito T, Hasebe T, Endoh Y, Sasaki H, Harigaya $\mathrm{K}$ and Ochiai $\mathrm{A}$ : In vivo and in vitro characterization of human fibroblasts recruited selectively into human cancer stroma. Int J Cancer 117: 212-220, 2005.
40. Mishra PJ, Mishra PJ, Humeniuk R, Medina DJ, Alexe G, Mesirov JP, Ganesan S, Glod JW and Banerjee D: Carcinomaassociated fibroblast-like differentiation of human mesenchymal stem cells. Cancer Res 68: 4331-4339, 2008.

41. Orimo A, Gupta PB, Sgroi DC, Arenzana-Seisdedos F, Delaunay T, Naeem R, Carey VJ and Richardson AL, Weinberg RA: Stromal fibroblasts present in invasive human breast carcinomas promote tumor growth and angiogenesis through elevated SDF-1/CXCL12 secretion. Cell 121: 335-348, 2005.

42. Ohira S, Sasaki M, Harada K, Sato Y, Zen Y, Isse K, Kozaka K, Ishikawa A, Oda K, Nimura Y and Nakanuma Y: Possible regulation of migration of intrahepatic cholangiocarcinoma cells by interaction of CXCR4 expressed in carcinoma cells with tumor necrosis factor- $\alpha$ and stromal-derived factor- 1 released in stroma. Am J Pathol 168: 1155-1168, 2006.

43. Marchesi F, Monti P, Leone BE, Zerbi A, Vecchi A, Piemonti L, Mantovani A and Allavena P: Increased survival, proliferation, and migration in metastatic human pancreatic tumor cells expressing functional CXCR4. Cancer Res 64: 8420-8427, 2004. 